\title{
Stock Price Short-term Forecasting Based On GARCH Model
}

\author{
Wanle Chi \\ Wenzhou Vocational \&Technical College, Wenzhou 325000, China. \\ 358455713@qq.com
}

Keywords: Forecasting, Stock Price, GARCH.

\begin{abstract}
Using the stock price data to set up a sequence to explain the relationship of stock price data, the future stock price can be forecasted. This paper conducts the real modeling research on the shanghai composite index utilized the GARCH-class models. The results of this paper had indicated that stock price undulation in the Shanghai Stock market has the obvious GARCH effect. The condition variance sequence of returns rate is stationary, the GARCH model has the predictability. And GARCH $(1,1)$ model may well in the fitting and the forecast the shanghai stock price index. This simulation model may realize the short-term high accuracy to forecast well that. The forecast value of shanghai index was closer to actual value, indicating that the GARCH model in the paper was a certain accuracy. This paper was helpful to dodge the risk regarding, and develop the profit space for the investors.
\end{abstract}

\section{Introduction}

In the stock market, the researchers have tried to find an effective forecast method of stock index, to dodging the risks, seizing the initiative, making the investment profit maximization. So, the study of stock index fitting, simulation and forecasting is a great significance to the investors and the development of disciplines.

The practice was shown that the time series of returns in the capital market is non-normal and thick tail. And it has volatility aggregation and persistence. If the fluctuation of current period is great, the fluctuation of next period will be great too. And it will be strengthened or weakened as the current yield deviates from the mean. Conversely, if the fluctuation of the current period is small, the fluctuation of the next period will be small, unless the current rate of return is seriously deviated from the mean.

The GARCH model not only makes up for the shortage of computational efficiency and precision caused by too many model order under the finite sample, but also has a good handling capacity of thick tail. The GARCH model has become one of the most important tools to measure the volatility of the financial market. This paper collected the daily closing price data of the shanghai composite index during the period of 2017-01-03 to 2017-12-15 (233 working days) and uses GARCH model to solve the forecast problem of shanghai composite index.

\section{The GARCH Model}

\subsection{The ARCH Model}

Engle (1980) proposed a new stochastic process model, which is called the autoregressive conditional heteroskedasticity model $(\mathrm{ARCH})$, which is used to capture the temporal and clustering characteristics of financial data. The formula of $\mathrm{ARCH}$ is as follow:

$$
\begin{gathered}
\mathrm{y}_{\mathrm{t}}=\mathrm{S}\left(\mathrm{y}_{\mathrm{t}-1}, \mathrm{y}_{\mathrm{t}-2}, \ldots\right) \varepsilon_{\mathrm{t}} \equiv \mathrm{h}_{\mathrm{t}}^{1 / 2} \varepsilon_{\mathrm{t}} \\
\mathrm{h}_{\mathrm{t}}=\alpha_{0}+\alpha_{1} \mathrm{y}_{\mathrm{t}-1}{ }^{2}+\alpha_{2} \mathrm{y}_{\mathrm{t}-2^{2}}+\ldots+\alpha_{\mathrm{p}} \mathrm{y}_{\mathrm{t}-\mathrm{p}}{ }^{2} \quad\left(\alpha_{0}>0, \alpha_{\mathrm{i}} \geq 0, \mathrm{i}=1,2, \ldots, \mathrm{p}\right)
\end{gathered}
$$

The $\varepsilon_{t}$ is the sequence of independent and identically distributed(i.i.d). $\varepsilon_{t} \sim N(0,1)$.

It was called ARCH (p). The $\mathrm{p}$ is the order of model.

\subsection{The GARCH Model}

Bollerslev (1986) proposed an improved ARCH model, which is called the generalized autoregressive conditional heteroskedasticity model(GARCH). The GARCH model add the 
autoregressive influence of heteroscedasticity itself into ARCH model. The GARCH model can describe most of the time series of financial returns. So it is widely used in the research of stock price's volatility. The formula of GARCH is as follow ${ }^{[1,2]}$ :

$$
\begin{gathered}
\mathrm{y}_{\mathrm{t}}=\mathrm{S}\left(\mathrm{y}_{\mathrm{t}-1}, \mathrm{yt}_{\mathrm{t}-2}, \ldots\right) \varepsilon_{\mathrm{t}} \equiv \mathrm{h}_{\mathrm{t}}^{1 / 2} \varepsilon_{\mathrm{t}} \\
\mathrm{h}_{\mathrm{t}}=\alpha_{0}+\alpha_{1} \mathrm{y}_{\mathrm{t}-1}{ }^{2}+\alpha_{2} \mathrm{y}_{\mathrm{t}-2}{ }^{2}+\ldots+\alpha_{\mathrm{p}} \mathrm{y}_{\mathrm{t}-\mathrm{p}}{ }^{2}+\beta_{1} \mathrm{~h}_{\mathrm{t}-1}+\ldots+\beta_{\mathrm{q}} \mathrm{h}_{\mathrm{t}-\mathrm{q}}\left(\alpha_{0}>0, \alpha_{\mathrm{i}} \geq 0, \mathrm{i}=1,2, \ldots, \mathrm{p} ; \beta_{\mathrm{j}} \geq 0, \mathrm{j}=1,2, \ldots, \mathrm{q}\right)
\end{gathered}
$$

\section{Data Description \& Test}

\subsection{The Original Data}

This paper collected the daily closing price data of the shanghai composite index during the period of 2017-01-03 to 2017-12-15 (233 working days) from the Chinese Finance \&Business Magazine ( http://app.finance.china.com.cn/stock/quote/history.php?code=sh000001\&begin_day=2017-0103\&end_day=2017-12-15 ). The first order difference of the closing price logarithm was used to measure the stock returns. There is a large number of rounding errors in the calculation, so the multiplication of 100 can reduce the error.

$$
\mathrm{R}_{\mathrm{t}}=\left(\ln \left(\mathrm{p}_{\mathrm{t}}\right)-\ln \left(\mathrm{p}_{\mathrm{t}-1}\right)\right)^{*} 100
$$

The $R_{t}$ is the returns of $t$ period. The $p_{t}$ is the daily closing price of $t$ period.

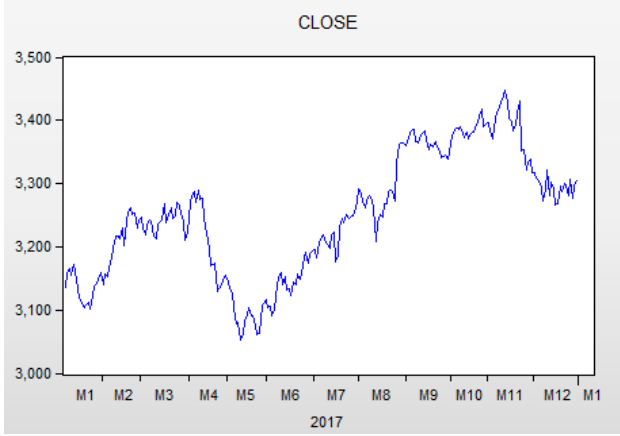

Fig.1 the graph of $p_{t}$

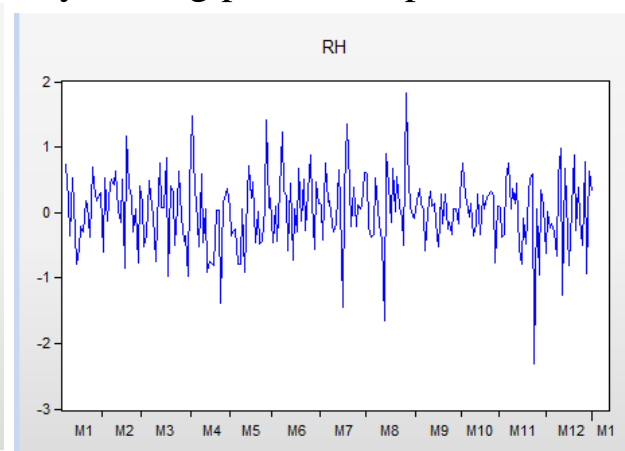

Fig. 2 the graph of $R_{t}$

From Fig. 1, the $p_{t}$ is a non-stationary time series. The sequence of $R_{t}$ may be stationary (Fig. 2).

\subsection{The Stationarity Test}

The ADF test is a commonly used unit root test method to test stationarity. A sequence which has a unit root is non-stationary. For a stationary time series data, it is necessary to reject the null hypothesis at a given confidence level. The formulas of ADF are as follows:

$$
\Delta \mathrm{u}_{\mathrm{t}}=\mathrm{c}+\delta \mathrm{u}_{\mathrm{t}-1}+\sum_{\mathrm{i}=1}^{\mathrm{p}-1} \beta_{\mathrm{i}} \Delta \mathrm{u}_{\mathrm{i}-1}+\varepsilon_{\mathrm{t}}
$$

The Formula (4) was be used to construct ADF test statistics.

$$
\mathrm{ADF}=\frac{\widehat{\delta}}{\mathrm{S}(\widehat{\delta})}
$$

The $\mathrm{S}(\widehat{\delta})$ is the sample standard deviation of $\delta$.

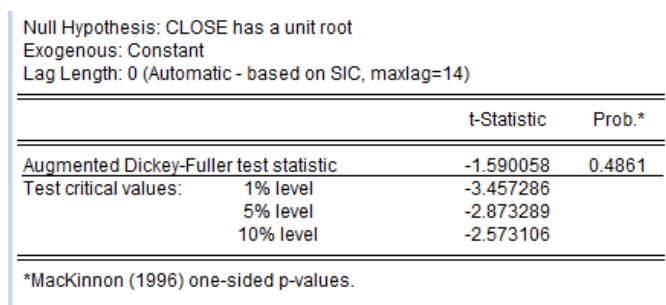

Fig. 3 the ADF test of $p_{t}$ Fig.4 the ADF test of $R_{t}$

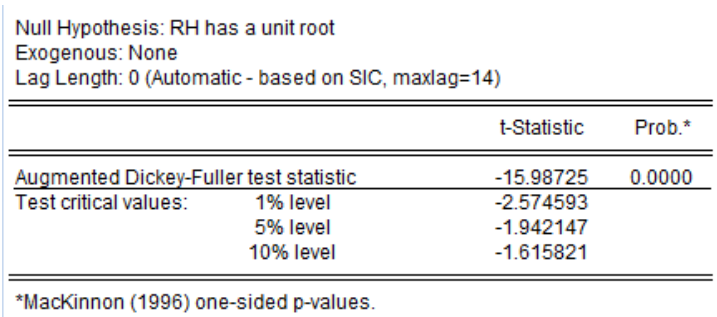

From Fig.3, it was shown that the $p_{t}$ has a unit root. The original hypothesis $(\delta=0)$ is accepted. And the $\mathrm{p}_{\mathrm{t}}$ sequence is non-stationary. From Fig.4, the ADF statistic absolute value (15.98725) was more than $1 \%$ level critical absolute value (2.574593). And the $\mathrm{p}$-value $(0.0000)$ of the $\mathrm{R}_{\mathrm{t}}$ sequence is less than 0.05 . The sequence of $\mathrm{R}_{\mathrm{t}}$ is stationary. 


\subsection{The Correlation Test}

From Fig.5, the autocorrelation and partial autocorrelation coefficients fall into the double estimated standard deviation. And the corresponding $\mathrm{p}$-values are more than confidence level 0.05.So there is no significant correlation in the significant level of the sequence at $5 \%$.

\begin{tabular}{|c|c|c|c|c|c|c|}
\hline Autocorrelation & Partial Correlation & & $\mathrm{AC}$ & PAC & Q-Stat & Prob \\
\hline 101 & 101 & 1 & -0.030 & -0.030 & 0.2180 & 0.641 \\
\hline 101 & 1 & 2 & -0.043 & -0.044 & 0.6696 & 0.715 \\
\hline 101 & 1 & 3 & -0.030 & -0.033 & 0.8912 & 0.828 \\
\hline 101 & 101 & 4 & -0.036 & -0.040 & 1.2121 & 0.876 \\
\hline 111 & 111 & 5 & -0.015 & -0.020 & 1.2655 & 0.938 \\
\hline 10 & י 1 1 & 6 & 0.102 & 0.097 & 3.8623 & 0.695 \\
\hline 101 & 101 & 7 & -0.031 & -0.029 & 4.1094 & 0.767 \\
\hline 1 & 101 & 8 & 0.031 & 0.036 & 4.3509 & 0.824 \\
\hline ים 1 & יק ו & 9 & 0.088 & 0.094 & 6.3105 & 0.708 \\
\hline 101 & 111 & 10 & -0.036 & -0.023 & 6.6348 & 0.759 \\
\hline 111 & $1 \mid 1$ & 11 & 0.011 & 0.021 & 6.6655 & 0.825 \\
\hline 叫 1 & 1 14 & 12 & -0.067 & -0.073 & 7.8308 & 0.798 \\
\hline
\end{tabular}

Fig.5 The autocorrelation diagram and partial autocorrelation diagram of $R_{t}$

There is no significant correlation in the sequence. the sequence of $R_{t}$ is a white noise sequence. The following model was established[3].

$$
\mathrm{R}_{\mathrm{t}}=\pi_{\mathrm{t}}+\varepsilon_{\mathrm{t}}
$$

Subtracting the average value of $\mathrm{R}_{t}$, the sequence of $\mathrm{W}_{t}$ established.

$$
\mathrm{W}_{\mathrm{t}}=\mathrm{R}_{\mathrm{t}}-0.021971
$$

0.021971 is the average value of $\mathrm{R}_{\mathrm{t}}$.

\subsection{The Heteroscedasticity Test}

From Fig.2, the distribution of $\mathrm{R}_{\mathrm{t}}$ has the characteristics of clustering. The fluctuation of $\mathrm{R}_{\mathrm{t}}$ was small in some time periods, and was very great in other time periods. It was shown that the sequence of $R_{t}$ had obvious heteroscedasticity. So, the ARCH test needs to be used to test the heteroscedasticity

\begin{tabular}{|c|c|c|c|c|c|c|}
\hline \multicolumn{7}{|c|}{ Correlogram of $\mathrm{ZH}$} \\
\hline \multicolumn{7}{|c|}{$\begin{array}{l}\text { Date: } 01 / 21 / 18 \text { Time: } 20: 53 \\
\text { Sample: } 1 / 03 / 2017 \text { 1/09/2018 } \\
\text { Included observations: } 242\end{array}$} \\
\hline Autocorrelation & Partial Correlation & & $A C$ & PAC & Q-Stat & Prob \\
\hline 叹 & 中 & 1 & 0.094 & 0.094 & 4.1885 & 0.041 \\
\hline 1 & ש1 & 2 & 0.130 & 0.122 & 12.233 & 0.002 \\
\hline 10 & 10 & 3 & 0.107 & 0.086 & 17.678 & 0.001 \\
\hline וקו & $1[1$ & 4 & 0.033 & 0.003 & 18.214 & 0.001 \\
\hline 19 & 19 & 5 & 0.086 & 0.062 & 21.759 & 0.001 \\
\hline 11 & 11 & 6 & 0.015 & -0.009 & 21.868 & 0.001 \\
\hline 10 & 1 & 7 & 0.075 & 0.057 & 24.608 & 0.001 \\
\hline 1/ 1 ו & 11 & 8 & 0.027 & 0.003 & 24.950 & 0.002 \\
\hline 10 1 ו & $1 \mid 1$ & 9 & 0.029 & 0.010 & 25.348 & 0.003 \\
\hline 19 & 101 & 10 & 0.059 & 0.038 & 27.042 & 0.003 \\
\hline 111 & $1 \mid 1$ & 11 & 0.017 & 0.003 & 27.186 & 0.004 \\
\hline 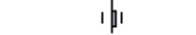 & 111 & 12 & 0.036 & 0.013 & 27.818 & 0.006 \\
\hline
\end{tabular}
of $R_{t}$. The sequence of $Z_{t}\left(Z_{t}=W_{t} \wedge 2\right)$ was established.

Fig.6 The autocorrelation diagram and partial autocorrelation diagram of $\mathrm{Z}_{\mathrm{t}}$

Fig. 6 was shown that the sequence has autocorrelation, which means that the original hypothesis is rejected. The sample has obvious heteroscedasticity. And there was ARCH effect.

\section{Forecasting by GARCH Model}

\subsection{The Determination Of Order}

It was necessary to determine the order, before the coefficient of GARCH was estimated. The AIC information criterion and the SC criterion were used to determine the order of model. The commonly used GARCH models include: $\operatorname{GARCH}(1,1), \operatorname{GARCH}(1,2), \operatorname{GARCH}(2,1)$. The results of each model were as follows: 


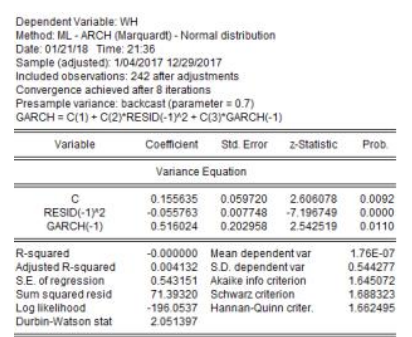

Fig.7 GARCH(1,1)

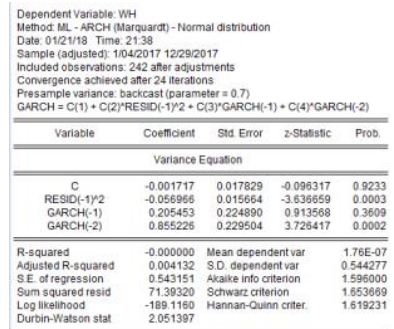

Fig. 8 GARCH(1,2)

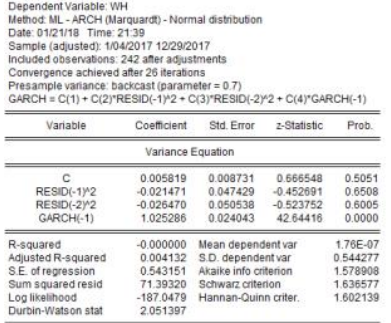

Fig.9 GARCH $(2,1)$

GARCH $(2,1)$ has the least value of AIC and the least value of SC. But some of GARCH $(2,1)$ coefficients were not passed by $T$ test. Same as $\operatorname{GARCH}(1,2)$ model. So $\operatorname{GARCH}(1,1)$ model was selected.

\subsection{The Residual Test}

The residual of GARCH $(1,1)$ model was tested by the ARCH effect test. The number 1, 4, 8, 12 were selected as the lag orders.

\begin{tabular}{llll}
\multicolumn{4}{l}{ Heteroskedasticity Test: ARCH } \\
\hline \hline F-statistic & 1.809970 & Prob. F(1,239) & 0.1798 \\
Obs*R-squared & 1.811398 & Prob. Chi-Square(1) & 0.1783 \\
\hline \hline
\end{tabular}

Fig.10 Residual Test : lag 1

Heteroskedasticity Test: ARCH

\begin{tabular}{llll}
\hline \hline F-statistic & 1.735762 & Prob. F(4,233) & 0.1429 \\
Obs*R-squared & 6.886823 & Prob. Chi-Square(4) & 0.1420 \\
\hline \hline
\end{tabular}

Fig.11 Residual Test : lag 4

Heteroskedasticity Test: ARCH

\begin{tabular}{llll}
\hline \hline F-statistic & 1.015902 & Prob. F(8,225) & 0.4248 \\
Obs*R-squared & 8.157644 & Prob. Chi-Square(8) & 0.4182 \\
\hline
\end{tabular}

Fig.12 Residual Test : lag 8

Heteroskedasticity Test: ARCH

\begin{tabular}{llll}
\hline \hline F-statistic & 1.033020 & Prob. F(12,217) & 0.4195 \\
Obs*R-squared & 12.42887 & Prob. Chi-Square(12) & 0.4119 \\
\hline \hline
\end{tabular}

Fig.13 Residual Test : lag 12

Under the test of various lag values, the F statistics are not significant. It was shown that the residual of GARCH $(1,1)$ model does not have the ARCH effect ${ }^{[4,5]}$.

\subsection{The Forecasting}

The static forecast values were as Table 1 .

Table 1 The static forecasting

\begin{tabular}{|c|c|c|c|c|c|}
\hline Date & Actual & Forecast & Difference & Absolute-dif & Abs-dif-percent \\
\hline $12 / 18 / 2017$ & 3307.17 & 3266.858 & 40.312 & 40.312 & 1.218927 \\
\hline $12 / 19 / 2017$ & 3296.39 & 3268.638 & 27.752 & 27.752 & 0.841891 \\
\hline $12 / 20 / 2017$ & 3275.78 & 3297.264 & -21.484 & 21.484 & 0.655844 \\
\hline $12 / 21 / 2017$ & 3306.12 & 3288.332 & 17.788 & 17.788 & 0.538032 \\
\hline $12 / 22 / 2017$ & 3280.46 & 3300.785 & -20.325 & 20.325 & 0.619578 \\
\hline $12 / 25 / 2017$ & 3297.06 & 3297.784 & -0.724 & 0.724 & 0.021959 \\
\hline $12 / 26 / 2017$ & 3300.06 & 3281.181 & 18.879 & 18.879 & 0.572081 \\
\hline $12 / 27 / 2017$ & 3287.61 & 3306.846 & -19.236 & 19.236 & 0.585106 \\
\hline $12 / 28 / 2017$ & 3296.54 & 3276.5 & 20.04 & 20.04 & 0.60791 \\
\hline $12 / 29 / 2017$ & 3267.92 & 3297.114 & -29.194 & 29.194 & 0.893351 \\
\hline
\end{tabular}

The results showed that the static forecast has a $0.655 \%$ of the average error rate. Considering the limit of the shanghai composite index, the maximum of error rate is $10 \%$. However, from the actual effect, it is not satisfying. It shows that the static of dynamic forecast is not good. 
The static forecast values were as Table 2 .

Table 2 The dynamic forecasting

\begin{tabular}{|c|c|c|c|c|c|}
\hline Date & Actual & Forecast & Difference & Absolute-dif & Abs-dif-percent \\
\hline $12 / 18 / 2017$ & 3307.17 & 3300.635 & 6.534512 & 6.534512 & 0.197586 \\
\hline $12 / 19 / 2017$ & 3296.39 & 3301.361 & -4.97075 & 4.97075 & 0.150794 \\
\hline $12 / 20 / 2017$ & 3275.78 & 3276.086 & -0.30617 & 0.306172 & 0.009347 \\
\hline $12 / 21 / 2017$ & 3306.12 & 3302.812 & 3.308247 & 3.308247 & 0.100064 \\
\hline $12 / 22 / 2017$ & 3280.46 & 3274.537 & 5.922507 & 5.922507 & 0.180539 \\
\hline $12 / 25 / 2017$ & 3297.06 & 3304.263 & -7.20339 & 7.203393 & 0.218479 \\
\hline $12 / 26 / 2017$ & 3300.06 & 3304.989 & -4.92945 & 4.929453 & 0.149375 \\
\hline $12 / 27 / 2017$ & 3287.61 & 3283.716 & 3.894328 & 3.894328 & 0.118455 \\
\hline $12 / 28 / 2017$ & 3296.54 & 3293.442 & 3.09795 & 3.09795 & 0.093976 \\
\hline $12 / 29 / 2017$ & 3267.92 & 3272.169 & -4.24859 & 4.248588 & 0.130009 \\
\hline
\end{tabular}

The results showed that the dynamic forecast has a $0.135 \%$ of the average error rate. These results were very satisfactory, considering.

\section{Conclusion}

The GARCH model to the volatility of returns sequence can be well fitted, and all the coefficients are significant. After GARCH regression, the heteroscedasticity of the residual can be eliminated. It was shown that the GARCH model is more effective in estimating and forecasting the volatility of stock returns in Chinese stock market.

\section{References}

[1]. Akgiray.V, Conditional Heteroskedasticity in Time Series of Stock Returns: Evidence and Forecasts. Journal of Business.Vol.62(1989)No.1,p.55-80.

[2]. Pagan.A.R ,Schwert.G.W, Alternative Models for Conditional Stock Volatilities. Journal of Econometrics. Vol.45(1990)No.6,p. 267- 290.

[3]. JinWen Zhao, Qian Wang, Emulation for the Shanghai 300 Stock Price Index Through the Shanghai 180 Stock Price Index by GARCH -Class Models. Research on Financial and Economic Issues. Vol.12(2008)No.3,p. 47- 54.

[4]. Men Kun, Empirical Analysis of Stock Price Based on ARMA Model, Journal of Hebei North University Vol.32(2016)No.5,p. 55- 60.

[5]. Jun Xu, Empirical Analysis of Gold Futures Price Based on ARMA Model, Industrial Economic Forum Vol.14(2017)No.3,p. 16- 21. 